\title{
Dentinal anomalies in teeth of harbour porpoises (Phocoena phocoena) from Scottish waters: are they linked to sexual maturation and environmental events?
}

\author{
P.L. LUQUE ${ }^{1,2}$, G.J. PIERCE ${ }^{1}$, J.A. LEARMONTH ${ }^{1}$, M.B. SANTOS ${ }^{1,3}$, E. IENO ${ }^{1,4}$, A. LÓPEZ ${ }^{5}$, R.J. REID ${ }^{6}$, \\ E. ROGAN ${ }^{7}$, A.F. GONZÁLEZ ${ }^{8}$, J. BOON ${ }^{9}$, R.J. LAW ${ }^{10}$ AND C.H. LOCKYER ${ }^{11}$ \\ ${ }^{1}$ School of Biological Sciences (Zoology), University of Aberdeen, Tillydrone Avenue, Aberdeen, AB24 2TZ, UK, ${ }^{2}$ Facultade de \\ Ciencias do Mar, Campus Universitario Lagoas-Marcosende, 36200 Vigo, Spain, ${ }^{3}$ Instituto Español de Oceanografía, Centro Costero \\ de Vigo, Cabo Estay, Canido, 36200 Vigo, Spain, ${ }^{4}$ Highland Statistics Ltd, 6 Laverock Road, Newburgh, Ellon, Aberdeenshire, \\ AB41 6FN, UK, ${ }^{5}$ CEMMA (Coordinadora para o Estudio dos Mamíferos Mariños), R/Tomás Mirambell 9o Paxón, 36340, Nigran, \\ Pontevedra (Spain), ${ }^{6}$ SAC Veterinary Science Division. Drummondhill, Stratherrick Road Inverness, IV2 4JZ, UK, ${ }^{7}$ ADC, \\ Department of Zoology, Ecology and Plant Science, University College, National University of Ireland, Lee Maltings, Prospect Row, \\ Cork, Ireland, ${ }^{8}$ Instituto de Investigaciones Marinas, Eduardo Cabello 6, 36208 Vigo, Spain, ${ }^{9}$ Royal Netherlands Institute for Sea \\ Research (NIOZ), P.O. Box 59, 1790 AB Den Burg, Texel, the Netherlands, ${ }^{\circ}$ The Centre for Environment, Fisheries and Aquaculture \\ Science, Cefas Burnham Laboratory, Remembrance Avenue, Burnham on Crouch, Essex CMo 8HA, UK, ${ }^{11}$ Age Dynamics, \\ Huldbergs Allé 42, DK-280o Kongens Lyngby, Denmark
}

\begin{abstract}
We examined the tooth ultra-structure of harbour porpoises (Phocoena phocoena) from Scottish waters to determine whether the incidence of mineralization anomalies could be related to certain life history events (e.g. the achievement of sexual maturation) as well as other factors that affect the general health of the individual (e.g. persistent organic pollutant (POP) concentrations in blubber). Five distinct types of mineralization anomalies were recorded: accessory lines, marker lines, dentinal resorption, cemental disturbance and pulp stones and the occurrence of these anomalies was scored by sex, age and maturity state. Overall, the incidence of mineralization anomalies was high and tended to increase with age. Marker lines and accessory lines were the most commonly recorded anomalies while pulp stones were least frequent. Duplicate teeth (i.e. from the same individual) always showed the same pattern of anomaly occurrence.

Fitted binary generalized linear and additive models indicated that the presence of dentinal resorption, cemental disturbance and marker lines in harbour porpoise teeth increased with age, body length and maturity. Males displayed marker lines more frequently than females. Age was the best predictor of the incidence of dentinal resorption and cemental disturbance while age and sex were the best predictors of the incidence of marker lines. The time course of appearance of dentinal resorption and cemental disturbance suggests that their occurrence could be related to physiological stress linked to sexual maturation. Marker lines were found within growth layer groups which coincided with the beginning of weaning and sexual maturation, suggesting an association with these two major life history events. Accessory lines were found in most teeth and may be a normal characteristic of porpoise teeth or reflect regular events. Pulp stones appeared only in mature animals. We found no evidence that the presence of anomalies in teeth was significantly related to POP concentrations in the blubber.
\end{abstract}

Keywords: dentinal anomalies, teeth, harbour porpoises, Scotland, sexual maturation, environmental events

Submitted 30 October 2006; accepted 7 March 2008; first published online 27 May 2009

\section{INTRDDUCTION}

Teeth provide a permanent record of cyclic and metabolic events throughout the life of the individual and they can easily be recovered from dead (and occasionally from living) animals (Hohn et al., 1989; Langvatan, 1995; Lockyer, 1999).

Corresponding author:

P.L. Luque

Email: p.lastra@abdn.ac.uk
The examination of tooth structures is routinely used in long-lived species such as marine mammals for age determination. The most obvious use of age is for estimating age-related parameters used in population dynamics models (Hohn, 2002). The questions explored here relate to additional information that can be obtained from cetacean teeth. In essence, the annual increments themselves are recording structures that reflect the physiology of an individual at the time of deposition (Klevezal, 1996). Several studies have shown that examination of the pattern of these incremental layers in dentine and/or cementum can provide information regarding general health, life history events (e.g. parturition, 
pregnancy, weaning and achievement of sexual maturation), environmental conditions and other forms of stress (e.g. the possible effects of exposure to increased contaminant levels) (Klevezal \& Myrick, 1984; Bengtson, 1988; Myrick, 1991; Lockyer, 1995a).

Age is estimated by counting growth layer groups (GLGs) (Perrin \& Myrick, 1980), which are thought to be laid down annually in the teeth of most odontocetes and formed as a result of seasonal changes in the growth rate of the tooth, correlated with seasonal changes in the individual's growth (Klevezal, 1980). The annual layers comprise more than simply a pair of adjacent light (broad) and dark (fine) staining bands: they can also contain daily layers or accessory layers as well as other alterations in the normal regular deposition rate of dentine and cement formed during an animal's life (Lockyer, 1995a; Klevezal, 1996; Hohn, 2002). In cetaceans (odontocetes) and sirenians, such disturbances or tooth-tissue alterations are termed mineralization anomalies.

Five different types of mineralization anomalies have been identified: accessory lines, marker lines, cemental disturbance, dentinal resorption and pulp stones (Myrick, 1988; Lockyer, 1993). Accessory lines are defined as additional distinct layers within a GLG which may stain light or dark. Pulp stones or osteodentine are discrete nodules, often containing concentric rings of secondary dentine. Generally these form in the region of the pulp cavity (Lockyer, 1995c). Marker lines or lines of Owen are found in both dentine and cementum. They are discrete regular lines noticeably different in appearance (e.g. staining deeply or not staining) from the boundary layers of the GLG (Lockyer, 1995c). Dentinal resorption refers to erosion and repair of existing regular laminated dentinal tissue, resulting in an amorphous and/or globular appearance, very often with holes, cutting across and into regular tissue, including mineralization interference that disrupts the usual patterns yet does not prevent continuous lamina formation (Myrick, 1988). Finally, cemental disturbance is defined as any anomalous appearance of the usual laminated cemental tissue, including mineralization interference and resorption (Myrick, 1988). Similar types of disturbance have been revealed in teeth of other mammals such as black bears (Ursus americanus), red deer (Cervus elaphus) and humans (Homo sapiens) (Myrick, 1988; Lockyer, 1999).

Several factors, including life history events (e.g. pregnancy, giving birth, being born, lactation, weaning and achievement of sexual maturity), sexual activity, prey availability, poor nutritional state and adverse environmental conditions, have been proposed as being responsible for the development of mineralization anomalies, since they have the potential to influence the growth of an individual. The mechanism could involve hormonal variations as well as effects on endogenous rhythms that, in turn, induce biochemical and physiological actions affecting the deposition of laminae in mammalian teeth. The pattern of dentine and cementum deposition could be affected since it depends on systemic calcium regulation (Myrick, 1988).

The presence of unusual layers within GLGs, indicating a link with life history events, has been reported in sperm whales (Physeter macrocephalus) (Klevezal et al., 1987), spotted dolphins (Stenella attenuata), spinner dolphins (Stenella longirostris) (Klevezal \& Myrick, 1984), and longfinned (Globicephala melas) and short-finned pilot whales (Globicephala macrorhynchus) (Lockyer, 1993). An association between mineralization anomalies in teeth and other causative factors (e.g. environmental factors) has been reported in dusky dolphins (Lagenorhynchus obscurus) (Manzanilla, 1989) and long-finned pilot whales (Lockyer, 1993). Other studies have suggested an association between anomalies and the concentration of organochlorine pollutants (PCB and DDTs) in body tissues (Stede \& Stede, 1990; Bergman et al., 1992).

In the present study we examined the tooth ultra-structure of harbour porpoises (Phocoena phocoena) from Scottish waters. The porpoise is the most common cetacean species in the region and therefore the species for which most samples were available. The objectives were: (a) to describe the time-course of accumulation of mineralization anomalies; and (b) to determine whether these anomalies could be related to life history events, particularly the achievement of sexual maturation, or to effects of bioaccumulation of organic pollutants. We scored teeth for the presence of five types of anomaly, focusing particularly on dentinal resorption and cemental disturbance, since it is thought that anomalies involving the resorption and transformation of existing dentinal tissues are caused by changes in physiological state, such as the hormone imbalance that occurs during sexual maturation.

\section{MATERIALS AND METHODS}

\section{Sampling}

Post-mortem examinations of stranded animals were conducted by the local strandings schemes. The Scottish Agricultural College (SAC) Veterinary Services at Inverness collected samples of harbour porpoises (Phocoena phocoena) stranded around the Scottish coastline between 2001 and 2005. The animals sampled included a range of age-classes from both sexes. Other data including date of stranding, sex and total body length were also recorded during examinations.

\section{Tooth preparation}

During post-mortem examination of each animal, at least 2-3 teeth were removed from the middle of the lower jaw and preserved in $10 \%$ neutral buffered formalin (Kuiken \& Hartmann, 1991). Teeth were prepared using a method adapted from Hohn \& Lockyer (1995). Firstly, the teeth were cleaned and then decalcified using a commercial decalcifying agent $(\mathrm{RDO} \otimes)$. The length of time required for decalcification varied between samples in relation to tooth size and age, with longer times required for larger and older individuals. Decalcification time ranged from 4-20 hours with shorter time for those teeth from juveniles and longer for teeth of adults. Once teeth were flexible and rubbery in texture, they were rinsed in running tap water for several hours. Then teeth were sectioned at 23-25 $\mu \mathrm{m}$ and mounted on freezing blocks with OCT (®Sakura Finetek) compound in a freezing $\left(-10^{\circ} \mathrm{C}\right)$ microtome (TE Electronic Cryostat). The teeth of harbour porpoise are spatulate in shape; therefore to ensure that optimum sections were obtained, two teeth were used for each individual and sectioned in two different orientations, one parallel to the mandible (porpoise cut) and one perpendicular (dolphin cut).

Multiple sections were obtained and only those that were the most central and complete, which included the crown and the maximum area of pulp cavity, were selected and stained using 
Mayer's haematoxylin (acidic). Stained sections were 'blued' in a weak ammonia solution and rinsed in distilled water. They were then mounted onto microscope slides pre-coated with $5 \%$ gelatine solution and dried on a warm hot plate (approximately $30^{\circ} \mathrm{C}$ ). Permanent slides were prepared using DPX-mountant surmounted by a glass cover slip.

\section{Age determination and identification of anomalies}

Decalcified and stained tooth sections were examined under a binocular microscope at $\times 40$ to $\times 100$ magnification. Age was estimated by counting GLGs in the dentine. The reading was done 'blind' (with no reference to biological data), by two readers (P.L.L. and J.A.L.), to avoid any possible biases in the estimation. The final estimated age was achieved by consensus between the two readers. In case of no consensus, an extra tooth was prepared and read. If no consensus was possible, the animal in question was excluded from further analysis.

Anomalies were classified following the criteria used by Myrick (1988) and Lockyer (1993, 1995C). In this study, up to 3 teeth were available from each individual and each tooth was examined for the presence of five types of anomalies: accessory lines, marker lines, dentinal resorption, cemental disturbance and pulp stones. In addition, we noted the growth layer groups (GLGs) in which accessory lines and marker lines appeared and the position of pulp stones in relation to the boundary of the GLGs in which they appeared.

\section{Analysis of reproductive status}

Reproductive organs (ovaries and testes) were collected during post-mortem examination for a total of 167 harbour porpoises for which age could also be determined (see Table 1). Both ovaries and testes were removed and preserved in $10 \%$ neutral buffered formalin. Reproductive organs were examined using methods adapted from Perrin \& Reilly (1984).

Before gross examination, the ovaries were rinsed in water for 24 hours and transferred to $70 \%$ ethanol. Both ovaries were examined externally to record the presence and number of corpora lutea (CL), corpora albicantia (CA) and any other features. Both ovaries were then hand-sectioned into $0.5-2 \mathrm{~mm}$ slices and examined internally under binocular microscope for the presence of CA and follicles. Females were considered to be sexually mature if the ovaries contained at least one CL or CA.

For histological processing of testes, a $1 \mathrm{~cm}^{3}$ block was dissected from the middle of each testis, with its associated

Table 1. Sample sizes for harbour porpoise teeth used for mineralization anomaly analysis displayed by sex and age-group. The table also gives sample sizes for animals for which measurements of persistent organic pollutants (POPs) in blubber were available.

\begin{tabular}{llcl}
\hline Age-group & Female & Male & Total \\
\hline 0-6 years & 43 & 47 & 90 \\
3-6 years & 19 & 8 & 27 \\
$\geq 6$ years & 24 & 26 & 50 \\
With POPs data & 31 & 19 & 50 \\
\hline
\end{tabular}

epididydmis. The tissue was dehydrated using 30\%, 50\%, $70 \%, 80 \%$ and $95 \%$ graded ethanol solutions, absolute ethanol and butanol. The samples were embedded in paraffin wax and $7 \mu \mathrm{m}$ sections cut. The sections were stained with haematoxylin and eosin and mounted on a glass slide using DPX. The slides were examined microscopically and individuals were categorized into maturity stages based on the methodology of Collet \& Saint-Girons (1984). Categorization was based on the relative proportion (low, medium and high) of Sertoli cells (which serve to nurture the germ cells through their cycles of development), interstitial tissue (between the tubules, where Leydig cells are found singly or in groups), germinal cells such as spermatogonia (the first phase and the most immature cells), spermatocytes (the second phase), spermatids (formed from secondary spermatocytes during meiosis) and spermatozoa (formed from spermatids during spermateliosis) (Wheater et al., 1987; Campbell, 1990; Hess, 1999), and the activity of the epididymis (the major site of storage of newly formed spermatozoa) (Wheater et al., 1987).

\section{Samples for persistent organic pollutant analysis}

As part of another project (BIOCET EVK3-2000-00027), blubber biopsies from selected animals that were classed as extremely fresh or only slightly decomposed (as defined by Kuiken \& Hartmann, 1991) were collected for contaminant analysis during 2001-2003. Most analysis of persistent organic pollutant (POP) concentrations was carried out at the Royal Netherlands Institute for Sea Research (NIOZ), with additional samples being analysed at The Centre for Environment, Fisheries and Aquaculture Science (CEFAS).

Organochlorine (DDT and $\mathrm{PCB}$ ) concentrations were determined based on methods from Allchin et al. (1989) and incorporating improvements validated within an intercomparison and method improvement programme conducted under the auspices of the International Council for the Exploration of the Sea.

During processing, lipids were extracted from the blubber samples using a mixture of pentane, dichloromethane and water. Lipid content was determined gravimetrically. Samples were cleaned by sulphuric acid treatment and elution over silica columns to separate the contaminants of interest from the lipids. Organochlorines (OCs) were determined by gas chromatography with electron capture detection (GC-ECD). The external standard mixture for the PCBs contained 39 congeners. Both NIOZ and CEFAS participated in 'round-robin' tests of analytical protocols in which both laboratories performed up to the current standard. Results from duplicate samples from the same animals analysed by both laboratories were similar.

The PCB concentrations used here for harbour porpoises are sums for concentrations of 16 compounds that were measured in both participating laboratories: $\mathrm{CB}_{2} 8, \mathrm{CB}_{49}$, $\mathrm{CB}_{52}, \mathrm{CB} 101, \mathrm{CB} 118, \mathrm{CB} 128, \mathrm{CB}_{13} 8$; $\mathrm{CB}_{141}, \mathrm{CB}_{149}$, $\mathrm{CB} 151, \mathrm{CB} 153, \mathrm{CB} 170, \mathrm{CB} 180, \mathrm{CB}_{183}, \mathrm{CB}_{187}$ and $\mathrm{CB} 194$, excluding compounds that were often below the limit of detection. Other OCs analysed included p,p'-DDE, which is the most persistent metabolite and the major representative of the insecticide DDT-group. At regular intervals, certified reference materials were analysed for PCBs and DDE. The values obtained all fell within the accepted normal ranges. 
For this study, measurements of POPs (DDT and PCBs) concentrations in blubber were available for 50 harbour porpoises for which teeth preparations were also available (see Table 1).

\section{Statistical analysis}

For some analyses, individuals were assigned to one of three age-classes: (i) class 1 which consisted of harbour porpoises from o to 3 years; (ii) class 2, which included animals from 3 to 6 years; and (iii) class 3 , which consisted of harbour porpoises aged older than 6 years.

Generalized linear modelling (McCullagh \& Nelder, 1989; Kleinbaum \& Klein, 2002) and generalized additive modelling (Hastie \& Tibshirani, 1990; Faraway, 2004; Wood, 2006; Zuur et al., 2007) using a binomial distribution and logit link function, were used to determine whether the incidence of each type of anomaly (response variables) could be linked with maturity state, age, total body length, sex and organochlorine contaminant concentrations in blubber (explanatory variables).

Initial data exploration indicated that age, total body length and maturity state are highly correlated with one another. According to Montgomery \& Peck (1992), high collinearity results in large variances for the regression coefficients. Therefore, separate models were fitted for each of the three main explanatory variables (i.e. age, length and maturity state).

Optimal models were selected on the basis of the lowest Akaike information criterion (AIC) provided that there were no serious patterns in residuals and all remaining explanatory variables had a significant effect. Where two models had very similar AIC values the more parsimonious model was preferred. Initially, GAMs were fitted, using cross-validation to determine the optimal degrees of freedom for smoothers. If all fitted smoothers had 1 degree of freedom (or close to 1 ), i.e. they were straight lines on the predictor scale, or all relationships with explanatory variables were non-significant, GLMs were also fitted and the optimal GLM identified. Data exploration, GLM and GAM were performed using Brodgar 2.5.2 (www.brodgar.com) and Minitab.

Since most final models were GLMs and did not include a significant effect of sex (except for marker lines), for visual presentation of 'anomaly ogives', we used the output from the GLMs relating anomaly incidence to age. Expected probabilities of anomaly occurrence-at-age $\left(p_{i}\right)$ for each of the $N$ porpoises were obtained using coefficients for intercept $(\alpha)$ and age $(b)$, and applying the inverse logit transformation:

$$
p_{i}=\frac{e^{a+b \times A g e_{i}}}{1+e^{a+b \times A g e_{i}}} \quad \text { where } \mathrm{i}=1, \ldots, \mathrm{N}
$$

We fitted similar models using length as a predictor. For visual comparison, a binary GLM was also fitted to maturity using age (or length) as an explanatory variable to create a maturity ogive.

\section{RESULTS}

\section{Age distribution and occurrence of anomalies}

Ages for both male and female porpoises ranged from less than one year up to 14 years old. The majority of the sample (approximately 60\%) was composed of porpoises aged 5 years old or less, with only $15 \%$ aged 10 years old and older (Figure 1). Thus not all age-classes were equally represented in the samples (see Table 2).

The presence of anomalies was high and generally increased with age in harbour porpoises. Furthermore, more than one tooth from the same individual was examined for the presence of mineralization anomalies and all the teeth showed the same type of alteration. Fitted binomial GLMs with age or length as the sole explanatory variable are illustrated for all anomaly types (Figures $2 \& 3$ ). It can be seen that, of all the anomalies, the time courses of appearance of dentinal anomalies and cemental disturbance were closest to the maturity ogive.

Accessory lines and marker lines were the most prevalent recorded anomalies in harbour porpoise. Approximately $94 \%$ of harbour porpoise teeth had accessory lines. The occurrence tended to increase with age in both sexes, although it was slightly higher in males. Accessory lines were seen in all animals over 3 years old. Accessory lines were most commonly seen within the first GLG, indicating that they begin to appear very early in life-and most animals already have accessory lines in their teeth prior to maturation.

Marker lines were recorded in $74 \%$ of harbour porpoise teeth examined. The incidence of marker lines increased with age and was slightly higher in males than in females. Marker lines appeared frequently within the first GLG, close to the neonatal line, and the third GLG (Figure 4).

Dentinal resorption and cemental disturbance were recorded in approximately $40 \%$ and $54 \%$ of harbour porpoise teeth examined, respectively. Overall, the incidence of these two anomalies tended to increase with age and was slightly higher in females than in males. Fitted GLMS indicated that the occurrence of dentinal resorption lagged slightly behind maturation although cemental disturbance tended to appear slightly ahead of maturation (Figure 2), being present in some immature animals (Table 2).

Pulp stones generally had a low frequency of occurrence, around $14 \%$, and were only seen in mature animals older than 6 years old. The incidence was higher in male than in female porpoises. The majority of porpoises with evidence of pulp stones had a pulp cavity that was almost closed and the pulp stones appeared either within the most recent GLGs or they remained free in the pulp cavity.

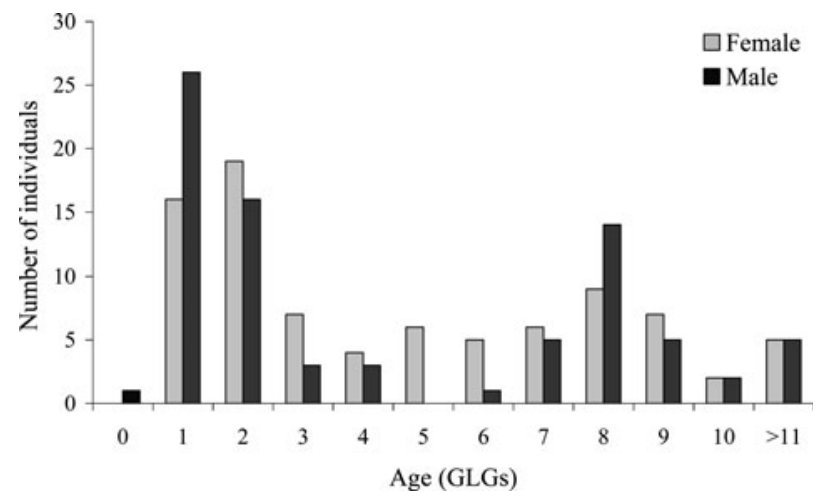

Fig. 1. Age-frequency distribution of male and female harbour porpoises from Scottish waters $(2001-2005)(\mathrm{N}=167)$. In each class, e.g. $2-3$, the age ranges from just above the lower value up to the higher value. 
Table 2. The occurrence of anomalies (\%) in 167 harbour porpoises ( $\mathrm{N}=86$ females and $\mathrm{N}=81$ males) displayed by age-class and sex ( $\mathrm{F}$, female; M, male; AL, accessory lines; CD, cemental disturbance; DR, dentinal resorption; ML, marker lines; PS, pulp stones). Number of teeth with anomaly in parentheses.

\begin{tabular}{|c|c|c|c|c|c|c|c|c|c|}
\hline \multirow[t]{2}{*}{ Anomalies } & \multicolumn{2}{|c|}{ Class 1 Age $(0-3)$} & \multicolumn{2}{|c|}{ Class 2 Age $(3-6)$} & \multicolumn{2}{|c|}{ Class 3 Age $>6$} & \multicolumn{3}{|l|}{ Total } \\
\hline & $\begin{array}{l}F \\
N=43\end{array}$ & $\begin{array}{l}M \\
N=47\end{array}$ & $\begin{array}{l}F \\
N=19\end{array}$ & $\begin{array}{l}M \\
N=8\end{array}$ & $\begin{array}{l}F \\
N=24\end{array}$ & $\begin{array}{l}M \\
N=26\end{array}$ & $\begin{array}{l}\text { Female with } \\
\text { anomalies }\end{array}$ & $\begin{array}{l}\text { Male with } \\
\text { anomalies }\end{array}$ & Overall \\
\hline DR & $5 \%$ & $4 \%$ & $68 \%$ & $75 \%$ & $88 \%$ & $85 \%$ & $42 \%$ & $37 \%$ & $40 \%(\mathrm{~N}=66)$ \\
\hline $\mathrm{CD}$ & $21 \%$ & $15 \%$ & $95 \%$ & $88 \%$ & $100 \%$ & $100 \%$ & $59 \%$ & $49 \%$ & $54 \%(\mathrm{~N}=91)$ \\
\hline ML & $56 \%$ & $74 \%$ & $84 \%$ & $75 \%$ & $75 \%$ & $92 \%$ & $68 \%$ & $80 \%$ & $74 \%(\mathrm{~N}=123)$ \\
\hline $\mathrm{AL}$ & $95 \%$ & $83 \%$ & $100 \%$ & $100 \%$ & $100 \%$ & $100 \%$ & $98 \%$ & $90 \%$ & $94 \%(\mathrm{~N}=157)$ \\
\hline PS & ०\% & o\% & $5 \%$ & $25 \%$ & $38 \%$ & $46 \%$ & $12 \%$ & $17 \%$ & $14 \%(\mathrm{~N}=24)$ \\
\hline
\end{tabular}

\section{Associations between anomalies, age, body size, sex and attainment of sexual maturity}

Modelling results confirmed that age, body length and maturity state were all significantly related to the presence of dentinal resorption, cemental disturbance and marker lines in teeth of Scottish porpoises.

The optimal model to explain the incidence of dentinal resorption used age as the sole predictor and explained 55\% of deviance. The best models using length or maturity as the predictor had higher AIC values and explained $50 \%$ and $40 \%$ of deviance, respectively (see Table 3 for details). Smoothers for the effects of age and length are illustrated in Figure 5.

For cemental disturbance, again the best model contained age alone and explained $65 \%$ of deviance. The best models using length or maturity as the predictor explained $58 \%$ and $42 \%$ of deviance, respectively (Table 3 ).

For the incidence of marker lines, the optimal model included effects of both age and sex and explained $17 \%$ of deviance. Males displayed marker lines more frequently than females. The best model using length also contained an effect of sex and explained $22 \%$ of deviance whereas the best model using maturity did not include sex and explained only $4 \%$ of deviance (Table 3 ).

In all cases, models confirmed that relationships between the incidence of these anomalies and age, body length or maturity were generally positive. Five of the nine best models summarized in Table 3 were GLMs (i.e. linear

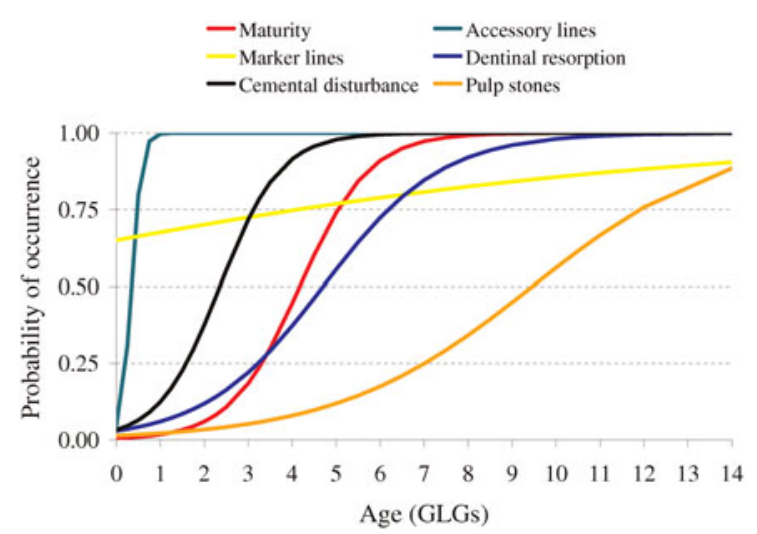

Fig. 2. Fitted logistic curves for the incidence of anomalies in harbour porpoise teeth in relation to age (data both sexes combined). Also shown is the fitted maturity ogive.

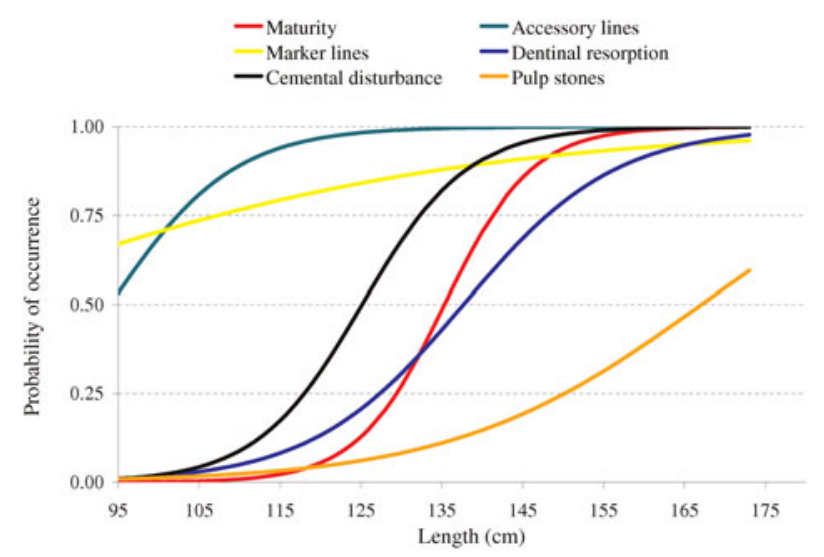

Fig. 3. Fitted logistic curves for the incidence of anomalies in harbour porpoise teeth in relation to length (data both sexes combined). Also shown is the fitted maturity ogive.

models) while in three out of four GAMs, the smoothers had around 2 degrees of freedom indicating relatively simple, monotonic curves. Note that a (linear) fit in a binomial GLM implies that the underlying relationship fits a logistic curve.

No satisfactory models could be fitted to data on the incidence of pulp stones or accessory lines due to the very unbalanced data sets (low incidence of pulp stones and high incidence of accessory lines).

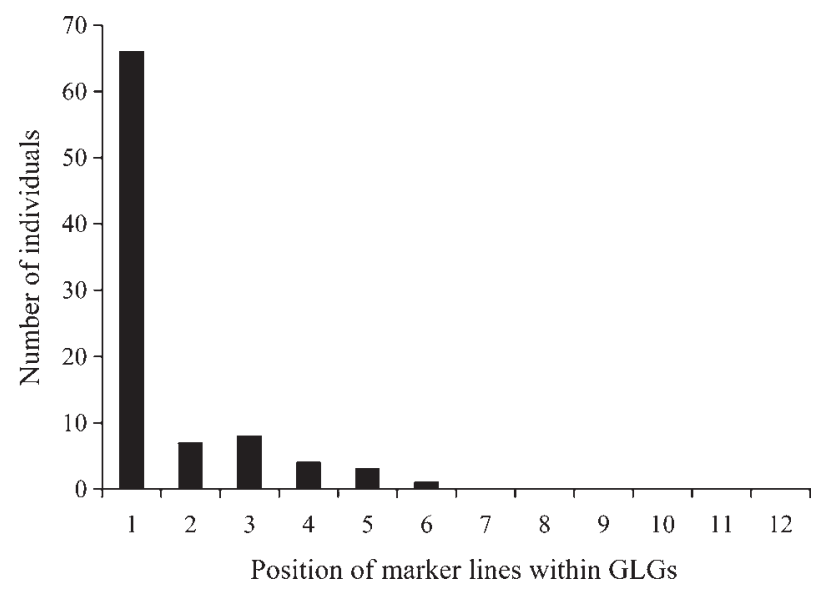

Fig. 4. Position of marker lines within annual or growth layer groups (GLGs) harbour porpoise teeth (data both sexes combined). 
Table 3. Generalized linear (GLM) and additive models (GAM) for the presence of anomalies (DR, dentinal resorption; $\mathrm{CD}$, cemental disturbance; ML, marker lines) in Scottish harbour porpoises $(\mathrm{N}=167)$. The table shows the best models based on age, length and maturity as predictors and gives the AIC values, \% deviance explained (\%DE) and parameter estimates (C, regression coefficient for linear relationships; DF, degrees of freedom for smoothers; P, probability; + or - indicates whether the smoother shows a generally positive or generally negative tendency).

\begin{tabular}{|c|c|c|c|c|c|}
\hline Anomaly & $\begin{array}{l}\text { Explanatory } \\
\text { variables }\end{array}$ & AIC & $\% \mathrm{DE}$ & Model & $\begin{array}{l}\text { Coefficients and } \\
\text { smoothers }\end{array}$ \\
\hline \multirow[t]{3}{*}{ DR } & Age & 108.14 & $54.70 \%$ & GAM & $\begin{array}{c}\mathrm{DF}=2.27(+) \\
P<0.001\end{array}$ \\
\hline & Length & 118.83 & $50.20 \%$ & GAM & $\begin{array}{c}\mathrm{DF}=2.57(+) \\
P<0.001\end{array}$ \\
\hline & Maturity & 138.43 & $40.00 \%$ & GLM & $\begin{array}{l}C=3.54 \\
\quad P<0.001\end{array}$ \\
\hline \multirow[t]{3}{*}{ CD } & Age & 83.91 & $65.28 \%$ & GLM & $\begin{aligned} \mathrm{C}=1.44 \\
\quad P<0.001\end{aligned}$ \\
\hline & Length & 100.04 & $58.27 \%$ & GLM & $\begin{array}{l}\mathrm{C}=0.15 \\
P<0.001\end{array}$ \\
\hline & Maturity & 137.31 & $42.03 \%$ & GLM & $\begin{array}{l}\mathrm{C}=4.21 \\
\quad P<0.001\end{array}$ \\
\hline \multirow[t]{3}{*}{ ML } & Age + sex & 125.30 & $17.00 \%$ & GAM & $\begin{array}{c}\mathrm{DF}_{\mathrm{age}}=2.16(+) \\
P=0.006 \\
\mathrm{C}_{\mathrm{sex}}=-1.27 \\
P=0.011\end{array}$ \\
\hline & Length + sex & 126.75 & $21.40 \%$ & GAM & $\begin{array}{c}\mathrm{DF}_{\text {length }}=5.94(+), \\
P=0.044 \\
\mathrm{C}_{\text {sex }}=-1.32, \\
P=0.015\end{array}$ \\
\hline & Maturity & 138.74 & $4.44 \%$ & GLM & $\begin{array}{l}\mathrm{C}=1.21 \\
\quad P=0.021\end{array}$ \\
\hline
\end{tabular}

\section{Association between anomalies and POP concentrations in blubber}

Measurements of DDE and PCB (the sum of 16 PCB congeners) concentrations in blubber were available for 50 harbour porpoises ( 31 females and 19 males) in the age-range o to 12 years old, with a higher representation of immature animals (approximately 64\%, $\mathrm{N}=32$ ) than mature. Application of GLM and GAM showed that neither PCB nor DDE concentrations contributed significantly to explaining the incidence of dentinal resorption or cemental disturbance in harbour porpoises. None of the previously fitted models were improved by adding DDE or PCB concentrations as explanatory variables and neither PCB nor DDE concentrations alone explained a significant part of the variation in incidence of any anomaly type.

\section{DISCUSSIDN}

\section{Dentinal resorption and cemental disturbance}

Overall, the occurrence of dentinal resorption and cemental disturbance tended to increase with age and the fitted GLMs showed that, at the population level, the time course of appearance of these anomalies was similar to the time course of maturation (see Figure 2). This might suggest a link between anomaly occurrence and the age at which the animals become sexually mature. Lockyer (1993) reported
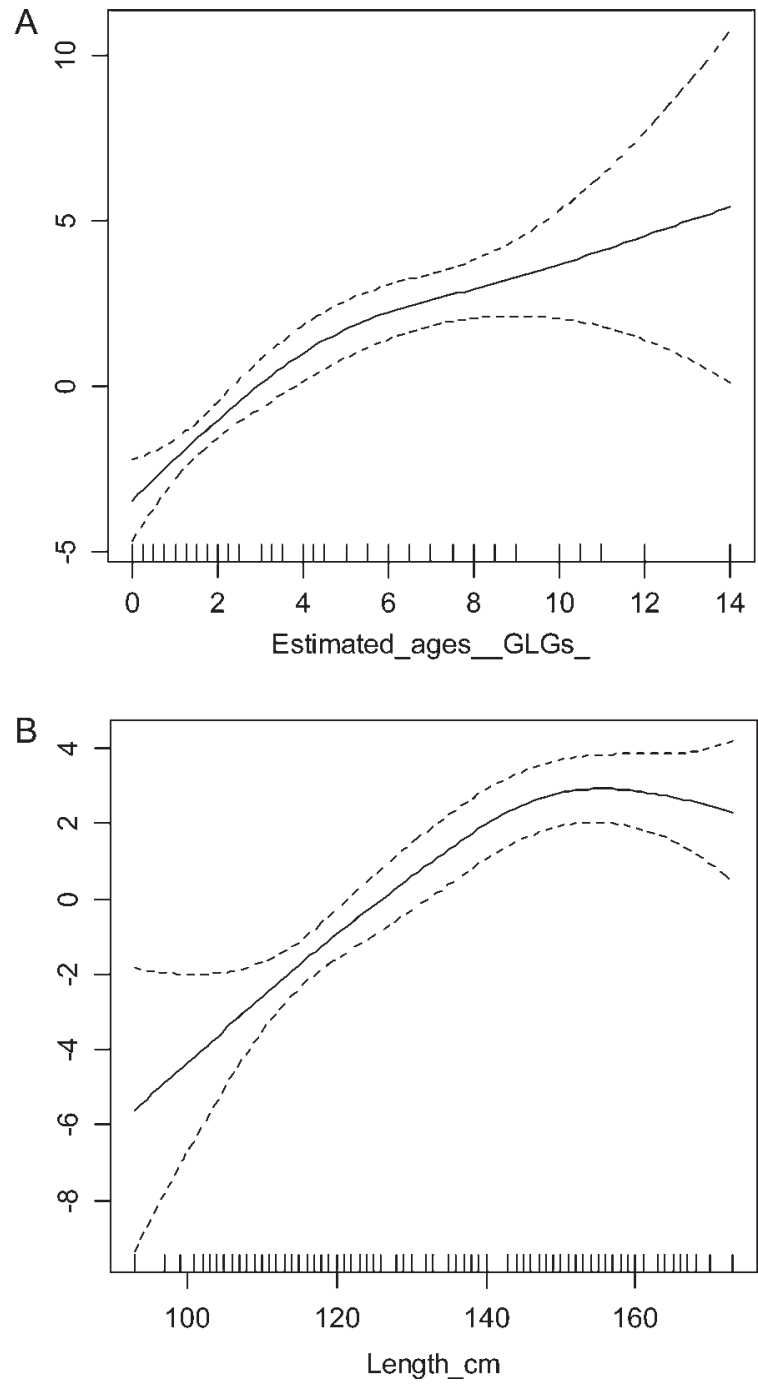

Fig. 5. Generalized additive models for occurrence of dentinal resorption in harbour porpoise teeth. Fitted smoothers (solid line) and 95\% confidence limits (broken lines) of the smooth term are shown for models based on: (A) age and (B) length.

that, in long-finned (Globicephala melas) and short-finned pilot whales (Globicephala macrorhynchus) from Iceland and the Faroes, dentinal resorption appeared in the teeth of all mature animals regardless of age, suggesting that it may be associated with hormonal changes that take place at the transition to adulthood.

In this study, fitted statistical models confirmed that the three co-varying life history variables (i.e. age, length or maturity) were all significantly related to the presence of dentinal resorption and cemental disturbance in Scottish harbour porpoises, although in both cases the best predictor for the incidence of anomalies was age. In addition, the fact that the relationships between anomaly incidence and age or length tended to be logistic curves rather than straight lines implies that there are certain ages and sizes at which anomalies have a higher probability of occurring. The youngest mature animals with evidence of dentinal resorption and cemental disturbance were aged around 4.5 and 4 years old respectively. Sexual maturity of harbour porpoises has been generally estimated to occur at between 3 and 4 years of age for both sexes (Lockyer, 2003). 
The fact that age is the best predictor of anomaly occurrence may indicate that maturation is responsible for the physiological conditions under which anomalies can arise but that the likelihood that an anomaly will occur continues to increase with age after maturation. The occurrence of dentinal resorption and cemental disturbance was slightly (but not significantly) more common in females than in males indicating that it could be related to the stresses associated with pregnancy, parturition or lactation. However, this requires further investigation.

Dentinal resorption and cemental disturbance were also recorded in a few immature animals. The youngest animal with evidence of anomalies was aged around 2 years old. This perhaps indicates the influence of other stressful factors (e.g. differences in feeding habits) that could affect the growth of the animal and in turn affect the growth of teeth (Lockyer, 1995c) or simply varying degrees of susceptibility to the same or different causative factors (Lockyer, 1993, 1995c). It is logical to suppose that mineral compounds in teeth as well as vitamins involved in the mineralization process derive from the mineral composition of food ingested (Klevezal, 1996). There is evidence that in Scottish waters, porpoises less than 1 year old feed more on gobies and shrimps than do older animals (Santos et al., 2004). A higher incidence of dentinal transformation (named sclerotic dentine) is reported in those species that feed more on fish than squid (Kleinenberg et al., 1964; Klevezal \& Phillips, 1986). Furthermore, experimental studies on the domestic goat (Capra hircus) (Lieberman, 1993) indicated that changes in diet or food composition determine changes in the rhythms of dentine formation, resulting in different degrees of mineralization. To date, there is insufficient information available for cetaceans to indicate whether differences in feeding habits and/or diet composition lead to variations in tooth structure. However, this topic merits further investigation, particularly working with animals in captivity, where diet is controlled.

Information available regarding the effects of stress on hard tissues in marine mammals is rare and generally open to some debate. Boschma (1950) investigated the possibility that resorption in sperm whale teeth was caused by physical external pressure from adjacent or opposing teeth. Boyde (1984) suggested that such physical pressure can create resorption and that the rate of erosion depends on the orientation and density of the mineralized tissue. He also demonstrated that resorption could be experimentally created in vitro using sperm whale dentine and osteoclasts from rabbit foetus. In his study, the frequency of occurrence of cemental disturbance was low in comparison to other recorded anomalies. In contrast, Lockyer (1995c) found a high incidence of cemental disturbance compared to other recorded anomalies, in all age-groups, suggesting that these anomalies may be a response to physical pressure and abrasion of the teeth as well as other causes. In the present study, when more than one tooth (up to 3 teeth) was available from an individual, each tooth usually showed the same forms and stages of alteration indicating that these features of tissue alteration observed were products of a systemic cause rather than local physical control (Myrick, 1988).

\section{Accessory lines}

Accessory lines were the most commonly recorded anomaly in harbour porpoise teeth and their incidence increased with age in both sexes, with females displaying accessory lines more frequently than males.

Accessory lines are considered to be 'false' incremental layers (but not annual) that occur within GLGs and which can be confused with the boundary of the annual layer leading to incorrect interpretations of age (Klevezal, 1980; Hohn et al., 1989). Therefore, for reliable age determination, it is essential to identify them (Hohn, 1990). In this study, several accessory lines were seen within different GLGs although they were more easily identified within the first GLG, as expected given that GLGs become narrower with increasing age, as they fill the pulp cavity, making it more difficult to identify them. Other studies have suggested that these incremental layers simply represent monthly records (Hohn, 1980; Klevezal, 1980; Myrick et al., 1984).

It has been suggested that the events that could cause the formation of accessory lines include maturation, pregnancy, weaning, as well as changes in diet or feeding (Hohn, 2002), which affect the animal's growth and in turn, influence the deposition of the collagen matrix or minerals in teeth. The presence of accessory lines within the first GLG might be associated with weaning, which takes place when porpoises are aged 8 and 11 months (Lockyer, 2003; Learmonth, 2006). However, the high frequency of occurrence of accessory lines in all age-classes of harbour porpoises might indicate that accessory lines represent intra-seasonal growth rate changes, as was suggested by Klevezal (1980). Rogan et al. (2004) found that harbour porpoises were more difficult to age in comparison to other species such as common dolphin (Delphinus delphis), striped (Stenella coeruleoalba) and bottlenose dolphins (Tursiops truncatus) from the north-east Atlantic, due to differences in banding pattern and presence of accessory lines. Differences in growth layer characteristics have also been observed in harbour porpoises from the Bay of Fundy, which have very distinct growth layer groups, in comparison to harbour porpoises from California (Hohn, 2002).

Another interpretation of the high incidence of accessory lines in all age-groups is that these anomalies may be responses to discrete short-term or recurrent problems from which recovery is prompt (e.g. changes in feeding habits) (e.g. Lockyer, 1993, 1995). Myrick (1991) examined dentinal and cemental layers in bottlenose dolphin teeth that were deposited during periods of sudden environmental fluctuations, for example, abrupt changes in water temperature, expecting to find alterations in the regular layering patterns. However, results showed that changes in water temperature had no perceptible effect on dentine deposition and no tooth alteration was detected. Further investigation is required to confirm this.

\section{Marker lines}

The incidence of marker lines was high and tended to increase with age. The optimal model for the incidence of marker lines included effects of age and sex, with males displaying marker lines more frequently than females. In most of the harbour porpoise teeth examined, marker lines were frequently identified within the first GLG, sometimes close to the neonatal line, although they also appeared within GLGs 2 and 3. A similar pattern of occurrence, in this case in GLGs for year one and years three to five, was reported by Lockyer (1995C) for harbour porpoises from different countries, suggesting 
that marker lines may be associated with life history events such as weaning and sexual maturity. This has also been suggested for the bottlenose dolphin (Hohn, 1980). From the literature, other life history events that have been associated with the presence of marker lines include 'parturition layers' linked to calving events in captive bottlenose dolphins (Myrick, 1991), as well as in spinner (Stenella longirostris) and spotted dolphins (Stenella attenuata) (Klevezal \& Myrick, 1984).

Other factors (e.g. environmental factors) may account for both the high incidence of marker lines and the lack of a clear relationship to maturity. The first convincing evidence of a connection between marker lines (or tooth anomalies) and environmental factors was reported by Manzanilla (1989). She observed the appearance of a hypocalcified layer within the 1983 GLG in adult female dusky dolphins (Lagenorhynchus obscurus), which she ascribed to dietary deficiencies due to the collapse of stocks of anchoveta (Engraulis ringens) during an El Niño period. Lockyer (1993) also reported the appearance of marker lines in teeth of longfinned pilot whale (Lockyer, 1993) in particular years. Lockyer $(1993,1995 \mathrm{C})$ also stated that the formation of marker lines may be influenced by a repetitive combination of internally generated and/or external environmental 'crises'. However, further examination is required to test these hypotheses.

\section{Pulp stones}

The incidence of pulp stones was generally low and no statistical models could be fitted to pulp stone data. Pulp stones were seen only in mature animals aged 6 years old and older. This might suggest a link with age at which the animal becomes sexually mature. Lockyer (1993) reported pulp stones in teeth of short-finned and long-finned pilot whales and she noted that the occurrence of pulp stones tended to be associated with the age at which puberty usually occurs, although no strong relationship with age was detected. The occurrence of pulp stones in older and mature individuals is also documented for the Boutu (Inia geoffrensis) (Silva, 1995), harbour porpoises (Lockyer, 1995C) and sperm whales (Physeter macrocephalus) (Evans et al., 2002). However, very little information is available on what factors might be responsible for their formation.

In the present study, the irregular incidence of pulp stones could indicate that they are not useful indicators of stress or other events. It was very difficult to estimate the age at which pulp stones occur because, in some porpoises, pulp stones were not yet embedded in the dentine and remained free in the pulp cavity. Lockyer (1995c) noted that pulp stones may remain free in the pulp cavity for a long period of time before becoming embedded in the dentine and perhaps the age at which pulp stones are formed may be earlier than they are identified in the dentine.

The irregularity and low incidence of pulp stones in teeth of Scottish porpoises is consistent with findings of Lockyer (1995c). She examined harbour porpoise teeth from different countries (i.e. the British Isles, Denmark, Canada, Norway and the USA (California)) and found that the pattern of increase in the incidence of pulp stones with age was not regular, suggesting that their occurrence might be an uncommon and spontaneous phenomenon.

\section{Effects of bioaccumulation of organic pollutants on the occurrence of mineralization anomalies}

In addition to those described above, other factors that might contribute to the incidence of dentinal resorption and/or cemental disturbance include the bioaccumulation of POPs (e.g. PCB and DDT) in cetacean tissues. In the present study, blubber POP concentrations were not related to the incidence of anomalies in harbour porpoise teeth, although the sample size available for analysis was small. Moreover, the sexes were not equally represented and most of the specimens were immature. In general POP concentrations are expected to be lower in mature females than mature males, who become increasingly contaminated as they grow older while females off-load contaminants to their offspring during pregnancy and lactation. This might explain the absence of a significant relationship between POP concentrations and the incidence of anomalies.

Persistent organic pollutants have been associated with pathological changes in the bones of harbour seals (Phoca vitulina) and the skulls of grey seals (Halichoerus grypus) (Stede \& Stede, 1990; Bergman et al., 1992). In porpoises, high PCB concentrations have been linked to disease- and parasite-related mortality (Hall et al., 2005; Jepson et al., 2005; Bull et al., 2006). Furthermore, among harbour porpoises from the British Isles, Denmark, Canada, Norway and California, the level of incidence of dentinal resorption was highest in porpoises from the areas where organochlorine levels were moderate, while in the areas where levels were low to moderate, there was a low incidence of resorption (Lockyer, 1995c).

\section{Overall incidence of anomalies}

The incidence of anomalies in porpoise teeth in the present study was generally high and tended to increase with age. Rogan et al. (2004) found a significantly higher incidence of tooth anomalies in harbour porpoises than in common, striped and bottlenose dolphins. It has been suggested that harbour porpoises may have a higher incidence of anomalies due to the structure of their teeth (spatulate compared to conical dolphin teeth) or it could relate to their more coastal habitat compared to the other species, which is perhaps exposing them to increased stress, greater environmental fluctuations or events and contaminants, which may influence the formation of anomalies (Rogan et al., 2004).

\section{ACKNOWLEDGEMENTS}

We are grateful to members of CEMMA (Coordinadora para o Estudio dos Mamíferos Mariños) in Galicia (north-west Spain) for the collection of material used for this study. Sample collection in Scotland and the POP analyses carried out at CEFAS were funded by DEFRA. Analysis of age, reproductive status and most analysis of POP concentrations were carried out as part of the EC-funded BIOCET project (EVK3-2000-00027). We thank Bill Edwards (School of Biological Sciences, University of Aberdeen) for technical support and advice. 


\section{REFERENCES}

Allchin C.R., Kelly C.A. and Portmann J.E. (1989) Methods of analysis for chlorinated hydrocarbons in marine and other samples. Aquatic Environment protection: analytical methods. Lowestoft: MAFF Directorate of Fisheries Research, 6, 25 pp.

Bengtson J.L. (1988) Long-term trends in the foraging patterns of female Antartic fur seals at South Georgia. In Sahrhage D. (ed.) Antarctic Ocean resource variability. Berlin: Springer-Verlag, pp. 286-291.

Bergman A., Olsson M. and Reiland S. (1992) Skull lesions in the Baltic grey seal (Halichoerus grypus). Ambio 21, 517-519.

Boshma H. (1950) Absorption of tooth tissue in the sperm whale Proceedings of the Koninklijke Nederlandse Akademie Van Wetenschappen 53, 289-293.

Boyde A. (1984) Dependence of rate physical erosion on orientation and density in mineralized tissues. Anatomy and Embryology 170, 57-62.

Bull J.C., Jepson P.D., Ssuna R.K., Deaville R., Allchin C.R., Law R.J. and Fenton A. (2006) The relationship between polychlorinated biphenyls in blubber and levels of nematode infestations in harbour porpoises, Phocoena phocoena. Parasitology 132, 565-573.

Campbell N.A. (1990) Biology, Second Edition. Redwood City, California: Benjamin/Cummings Publishing Company, Inc., 1165 pp.

Collet A. and Saint-Girons H. (1984) Preliminary study of the male reproductive cycle in common dolphins, Delphinus delphis, in the Eastern North Atlantic. In Perrin W.F., Brownell R.L.J. and DeMaster D.P. (eds) Reproduction in whales, dolphins and porpoises. Report of the International Whaling Commission Special Issue 6, Cambridge: International Whaling Commission, pp. 355-360.

Evans K., Hindall A.M., Bobertson K., Lockyer C. and Rice D. (2002) Factors affecting the precision of age determination of sperm whales (Physater macrocephalus). Journal of Cetacean Research and Management 4, 193-201.

Faraway J.J. (2004) Linear models with R. Boca Raton, FL: Chapman \& Hall/CRC.

Hall A.J., Hugunin K., Deaville R., Law R.J., Allchin C.R. and Jepson P.D. (2006) The risk of infection from polychlorinated biphenyl exposure in harbor porpoise (Phocoena phocoena): a case-control approach. Environmental Health Perspectives 114, 704-711.

Hastie T.J. and Tibshirani R.J. (1990) Generalized additive models. London: Chapman \& Hall.

Hess R.A. (1999) Spermatogenesis, overview. In Knobil E. and Neill J.D. (eds) Encyclopedia of reproduction. Volume 4. New York: Academic Press, pp. 539-545.

Hohn A.A. (1980) Age determination and age related factors in the teeth of Western North Atlantic bottlenose dolphins. Scientific Reports of the Whales Research Institute, Tokyo 32, 39-66.

Hohn A.A. (1990) Reading between the lines: analysis of age estimation in dolphins. In Leatherwood S. and Reeves R.R. (eds) The bottlenose dolphins, Volume 33. New York: Academic Press, pp. 578-585.

Hohn A.A. (2002) Age estimation. In Perrin W.F., Würsig B. and Thewissen J.G.M. (eds) Encyclopedia of marine mammals. San Diego: Academic Press, pp. 6-13.

Hohn A.A and Lockyer C. (1995) Protocol for obtaining age estimates from harbour porpoise teeth. Appendix 3, Report of the harbour porpoise age determination workshop. In Bjørge A. and Donovan G.P. (eds) Biology of phocoenids. Report of the International Whaling Commission, Special Issue 16. Cambridge: International Whaling Commission, pp. $478-493$.
Hohn A.A., Scott M.D., Wells R.S., Sweeney J.S. and Irvine A.B. (1989) Growth layers in the teeth from known-age, free-ranging bottlenose dolphins. Marine Mammal Science 5, 315-342.

Jepson P.D., Bennett P.M., Deaville R., Allchin C.R., Baker J.R. and Law R.J. (2005) Relationships between polychlorinated biphenyls and health status in harbor porpoises (Phocoena phocoena) stranded in the United Kingdom. Environmental Toxicology and Chemistry $24,238-248$

Kleinbaum D.G. and Klein M. (2002) Logistic regression: a self-learning text. New York: Springer-Verlag.

Kleinenberg S.E., Yablokov A.V., Bel'Kovich V.M. and Tarasevish M.N. (1964) Beluga (Delphinapterus leucas). Investigation of the species. M. Nauka. Translated from Russian in 1969. Jerusalem: Israel Program for Scientific Translations.

Klevezal G.A. (1980) Layers in the hard tissues of mammals as a record of growth rhythms of individuals. In Perrin W.F. and Myrick A.C. (eds) Age determination of toothed whales and sirenians. Report of the International Whaling Commission, Special Issue 3. Cambridge: International Whaling Commission, pp. 89-94.

Klevezal G.A. (1996) Recording structures of mammals: determination of age and reconstruction of life history. Rotterdam: A.A. Balkema. $274 \mathrm{pp}$.

Klevezal G.A. and Myrick A.C. (1984) Marks in tooth dentine of female dolphins (Genus Stenella) as indicators of parturition. Journal of Mammology 65, 103-110.

Klevezal G.A. and Phillips C.J. (1986) The nature of sclerotic dentine in the teeth of mammals: new clues to life history. In 66th Annual Meeting of American Society of Mammologists. 15-19 June 1986. Abstract 41

Klevezal G.A., Sukhovskaya L.I. and Vilenkin A.Ya. (1987) [Structure of "marks of breeding" in Odontoceti dentine]. Zoologichesky Zhurnal 66, 1886-1891. [In Russian.]

Klevezal G.A. and Tormosov D.D. (1971) [Revealing of local groups of sperm whale by growth layer patterns in tooth dentine]. Trudy Atlant NIRO 39, 35-43. [In Russian.]

Kuiken T. and Hartmann M.G. (1991) Cetacean pathology: dissection techniques and tissue sampling. In Proceedings of the first European Cetacean Society workshop on cetacean pathology: dissection techniques and tissue sampling, Leiden, The Netherlands. European Cetacean Society Newsletter no. 17

Langvatan R. (1995) Age determination of mammals-some aspects of biochemistry and physiological mechanisms relating to deposition of incremental lines in dental tissue. In Bjørge A. and Donovan G.P. (eds) Biology of phocoenids. Report of the International Whaling Commission, Special Issue 16. Cambridge: International Whaling Commission, pp. 499-509.

Learmonth J.A. (2006) Life history and fatty acid analysis of harbour porpoises (Phocoena phocoena) from Scottish waters. PhD thesis, University of Aberdeen, Aberdeen.

Lieberman D.E. (1993) Life history variables preserved in dental cementum microstructure. Science 261, 1962-1964.

Lockyer C. (1993) A report on patterns of deposition of dentine and cement in teeth of pilot whales, genus Globicephala. In Donovan G.P., Lockyer C.H. and Martin A.R. (eds) Biology of Northern Hemisphere Pilot Whales. Report of the International Whaling Commission, Special Issue 14. Cambridge: International Whaling Commission. pp. 137-161

Lockyer C. (1995a) Investigations of aspects of the life history of harbour porpoise, Phocoena phocoena, in British waters. In Bjørge A. and Donovan G.P. (eds) Biology of phocoenids. Report of the 
International Whaling Commission, Special Issue 16. Cambridge: International Whaling Commission, pp. 189-197.

Lockyer C. (1995c) A review of factors involved in zonation in odontocete teeth, and an investigation of the likely impact of environment factors and major life events on harbour porpoise tooth structure. In Bjørge A and Donovan G.P. (eds) Biology of phocoenids. Report of the International Whaling Commission, Special Issue 16. Cambridge: International Whaling Commission, pp. 511-529.

Lockyer C. (1999) Application of a new method to investigate population structure in the harbour porpoise, Phocoena phocoena, with special reference to the North and Baltic seas. Journal of Cetacean Research and Management 1, 297-304.

Lockyer C. (2003) Harbour porpoise in the North Atlantic: biological parameters. NAMMCO Scientific Publications 5, 71-90.

Manzanilla S.R. (1989) The 1982-1983 El Niño event recorded in dentinal growth layers in teeth of Peruvian dusky dolphins (Lagenorhynchus obscurus). Canadian Journal of Zoology 67, 21202125 .

McCullagh P. and Nelder J.A. (1989) Generalized linear models, 2nd edition. London: Chapman \& Hall.

Montgomery D.C. and Peck E.A. (1992) Introduction to linear regression analysis, 2nd edition. New York: John Wiley \& Sons.

Myrick A.C. Jr (1988) Is tissue resorption and replacement in permanen teeth of mammals caused by stress-induced hypocalcemia? In Davidovitch Z. (ed.) The biological mechanisms of tooth eruption and root resorption. Birmingham, Alabama: EBSCO Media, pp $379-389$.

Myrick A.C. Jr (1991) Some new and potential uses of the dental layers in studying delphinid populations. In Pryor K. and Norris K.S. (eds) Dolphin societies: discoveries and puzzles. Berkeley and Los Angeles: University of California Press, pp. 251-279.

Myrick A.C. Jr, Shallenberger E.W., Kang I. and Mackay D.B. (1984) Calibration of dental layers in seven captive Hawaiian spinner dolphin Stenella longirostris, based on tetracycline labeling. Fisheries Bulletin 82, 207-225.

Perrin W.F. and Donovan G.P. (1984) Report of the workshop on reproduction of whales, dolphins and porpoises. In Perrin W.F., Brownel R.L. and De master D.P. (eds) Reproduction in whales, dolphin and porpoises. Report of the International Whaling Commission, Special Issue 6. Cambridge: International Whaling Commission, pp. 1-24.

Perrin W.F. and Myrick A.C. Jr (1980) Age determination of toothed whales and sirenians. In Perrin W.F. and Myrick A.C. (eds) Age determination of toothed whales and sirenians. Report of the International
Whaling Commission, Special Issue 3. Cambridge: International Whaling Commission, pp. 1-50.

Perrin W.F. and Reilly S.B. (1984) Reproductive parameters of dolphins and small whales of the family Delphinidae. Reproduction in whales, dolphins and porpoises. In W.F. Perrin, J.R.L. Brownell and D.P. DeMaster (eds) Report of the International Whaling Commission Special Issue 6, 97-125.

Rogan E., Murphy S., Learmonth J.A., Gonzalez A. and Dabin W. (2004) Age determination in small cetaceans from the NE Atlantic. BIOCET Workpackage 4-final report. Bioaccumulation of persistent organic pollutants in small cetaceans in European waters: transport pathways and impact on reproduction. Project Reference: EVK3-2000-00027. 34 .

Santos M.B., Pierce G.J., Learmonth J.A., Reid R.J., Ross H.M., Patterson I.A.P., Reid D.G. and Beare D. (2004) Variability in the diet of harbour porpoises (Phocoena phocoena) in Scottish waters 1992-2003. Marine Mammal Science 20, 1-27

Silva V.M.F. (1995) Age estimation of the Amazon dolphin Inia geoffrensis, using laminae in the teeth. In Bjørge A. and Donovan G.P. (eds) Biology of phocoenids. Report of the International Whaling Commission, Special Issue 16. Cambridge: International Whaling Commission, pp. 531-543.

Stede G. and Stede M. (1990) Oreintuerenede Untersuchungen von Seehundschädeln auf pathologische Knochenveränderungen (Orientating investigations on harbour seal skulls regarding pathological bone changes). In Zoologishe und Ethologische Untersuchungen zum Roggensterben. Kiel, Germany: Institute fur Haustierkunde, pp. $31-53$.

Wheater P.R., Burkitt H.G. and Daniels V.G. (1987) Functional histology. Edinburgh: Churchill Livingstone.

Wood S.N. (2006) Generalized additive models: an introduction with R. Boca Raton, FL: Taylor \& Francis Ltd.

and

Zuur A.F., Ieno E.N. and Smith G.M. (2007) Analysing ecological data. New York: Springer.

\section{Correspondence should be addressed to:} P.L. Luque

School of Biological Sciences (Zoology)

University of Aberdeen

Tillydrone Avenue, Aberdeen, AB24 2TZ, UK

email: p.lastra@abdn.ac.uk 